\title{
Endoscopic Ultrasonography of Malignant Rectal Tumors for the Decision-Making of Therapeutic Action
}

\section{Norberto Caridad Alfonso Contino ${ }^{1}$, Raúl Antonio Brizuela Quintanilla ${ }^{2 *}$, Jorge Luis García Menocal ${ }^{3}$, Yanet Ortega Dugrot $^{4}$, Julieth Suarez Oceguera ${ }^{5}$ and Marelys Beatriz Estupiñan Álvarez ${ }^{6}$}

${ }^{1}$ Doctor of Medicine, $1^{\text {st }}$ Grade Specialist in MGI and Gastroenterology, Assistant Professor and Researcher Added, University of Medical Sciences of Havana, Minimum Access Surgery Center, Havana, Cuba

${ }^{2}$ Doctor of Medicine, $2^{\text {nd }}$ Grade Specialist in Gastroenterology, Doctor of Medical Sciences, Principal Researcher, Associate Professor, Minimum Access Surgery Center, University of Medical Sciences of Havana, Minimum Access Surgery Center, Havana, Cuba

${ }^{3}$ Doctor of Medicine, $2^{\text {nd }}$ Grade Specialist in Gastroenterology, Assistant Researcher Assistant Professor Minimum Access Surgery Center, University of Medical Sciences of Havana, Minimum Access Surgery Center, Havana, Cuba

${ }^{4}$ Degree of Nursing, Aggregate Researcher, Assistant Teacher, Minimum Access Surgery Center, University of Medical Sciences of Havana, Minimum Access Surgery Center, Havana, Cuba

${ }^{5}$ Degree in Imaging, Endoscopic Surgery Center, Cuba

${ }^{6}$ Degree in English, Master in Higher Education in Health Sciences, Assistant Professor FCM Julio Trigo López, Cuba

*Corresponding Author: Antonio Brizuela Quintanilla, Doctor of Medicine, $2^{\text {nd }}$ Grade Specialist in Gastroenterology, Doctor of Medical Sciences, Principal Researcher, Associate Professor, Minimum Access Surgery Center, University of Medical Sciences of Havana, Minimum Access Surgery Center, Havana, Cuba.

Received: September 13, 2019; Published: October 15, 2019

DOI: $10.31080 /$ ASGIS.2019.02.0090

\begin{abstract}
Introduction: In Cuba the rectal tumor occupies the fourteenth cause of death among malignant and fifth tumors among malignant digestive tumors and its proper management depends on its staging. At present, endoscopic ultrasonography has a very well defined diagnostic value in the preoperative staging of rectal cancer, its introduction increases the ability to delimit the rectal wall layers, which allows to evaluate the depth of the invasion, as well as the presence of regional lymphatic metastases.

Objective: To analyze the usefulness of endoscopic ultrasonography in the staging of patients with malignant rectal tumors.

Development: Staging by endoscopic ultrasonography of malignant tumors of the rectum allows to assume appropriate therapeutic behaviors (radiochemotherapy or surgery).

Conclusions: In this study it is expected to find that the staging by endoscopic ultrasonography of rectal tumors, helps in the decision of the use of adequate therapy.

Keywords: Endoscopic Ultrasound; Rectal Cancer; Staging; Therapeutic Action
\end{abstract}

\section{Introduction}

Colorectal cancer is the most common tumor of the digestive tract in the developed world, the rectum being the most affected site. It is the third cancer that is diagnosed most frequently in the United States, Europe and Cuba [1].

In Cuba this pathology is among the first five causes of morbidity and mortality due to digestive cancer, occupying the fourteenth place as the cause of death [2]. In addition to being a subject little explored so far its incidence is increasing more and more.

This cancer variety has a high rate of local recurrence after surgery, which varies between $30 \%$ and $65 \%$ in different studies. It has been shown that those patients with locally advanced rectal cancer (stages T3-4Nx or TxN1-2) have a lower rate of tumor recurrence and greater survival when they are given preoperative neoadjuvant cancer treatment. So there are multiple imaging techniques that help us both to the initial diagnosis and to the ideal management of this patient. It is therefore vital to carry out a precise preoperative staging of rectal cancer, being today the endoscopic ultrasonography (USE) one of the examinations that offers a better diagnostic accuracy for this purpose. The diagnostic accuracy of EUS for T staging varies between 69 and 97\%, while for N staging it is around $70-75 \%[3]$.

It is usual that the first studies published on the subject of a new technique usually offer excellent results $[4,5]$, while the generalization in the use of this technique and a moderation of the initial en- 
thusiasm lead to more variable results, since often less impressive in terms of diagnostic accuracy [6]. In this regard and regarding the role of EUS in rectal cancer, we can see in the literature consulted that there is an inverse relationship between the diagnostic accuracy obtained and the sample size of the different studies. In addition, the highest diagnostic accuracies are found in the oldest studies, possibly related to the previously mentioned phenomenon. A possible explanation for these facts is that there is a publication bias so that those studies with the best results tend to be published, even if the sample size is small [7]. In this way, it can be thought that the actual ability of the USE to carry out a Correct rectal cancer staging is lower than that published in the literature.

However, in relation to the above, the authors consider that EUS is a novel technique, advantageous in the staging of rectal tumors, which offers useful information about the disease, which favors accurate diagnoses that facilitate decision making, as for therapeutic or possible surgery.

EUS is one of the techniques that offers the highest diagnostic accuracy for staging of rectal cancer, this is one of the main indications for EUS screening [3]. Comparative studies have been published in which EUS has demonstrated its superiority for T staging of rectal cancer with respect to CT [1], and values higher or similar to MRI. It is true that the NMR has experienced a significant improvement in its results with the technological advances incorporated. The high resolution NMR improves the results obtained with NMR with rectal or body coil [8], today constitutes a good alternative to EUS. 9 The problem of MRI is its high cost, limited availability and its discrete results in the staging of early stage tumors when compared to EUS $[9,10]$. In return, it allows a complete study of the entire mesorectum, is less operator dependent than the USE, and identifies the involvement of the mesorectal fascia and therefore can determine the indemnity of the circumferential resection margin [11].

In this regard, the authors agree that MRI offers a more comprehensive diagnosis of the disease, however it is more expensive and difficult to access, which is a major disadvantage with respect to EUS.

This research aims to analyze the usefulness of endoscopic ultrasonography in the staging of patients with malignant rectal tumors.

\section{Development}

Colorectal cancer is the third most common cause of malignancy, the fourth leading cause of death and the second leading cause of tumor worldwide [2]. According to the results presented in the statistical health yearbook of 2017, in Cuba, 2,485 deaths from cancer of the digestive system are reported except for the rectum with a figure of 378 , with an annual rate of 22.7 per 100,000 inhabitants and straight with 3.4 per 100000 inhabitant. The figure represents 156 cases more than in 2016. This type of cancer constitutes the fourth cause of mortality from malignant tumors in the country, after those of prostate, lung and breast. It predominates in women where 1436 deaths are reported, with a rate of 25.4 per 100,000 inhabitants; while, in men, 1,049 deaths, with a rate of 18.7 per 100,000 inhabitants [2].

In addition, 381 deaths are reported whose location was distributed between the rectosigmoid portion and the anus, with a rate of 3.4 deaths per 100000 inhabitants. They occupy the fourteenth cause of death among other malignant tumors. Of these deaths, 226 were women, with a rate of 2.9 per 100,000 inhabitants, while in men 152 deaths were reported, with a rate of 2.7 per 100,000 inhabitants. For this reason, the Cuban health authorities promote the study of the lesions that could evolve towards this disease, as well as the risk factors that influence its genesis [2].

In this sense, the current interest of the world scientific community to study patients with rectal tumor is given to be the most common location of the primary tumor is treatable and often curable when it is located early. The appropriate management depends on the staging of the tumor and the prognosis, related to the degree of penetration of the tumor through the intestinal wall and the presence or not of adenopathies, facts that rest on a rich literature review of studies conducted in different parts of the world that They report and show that the success of the therapy in these patients is in staging [12-13].

The staging of rectal cancer in $\mathrm{T}$ and $\mathrm{N}$ forms the basis of the entire staging system developed for this disease, whose precision influences therapeutics, helping to determine which patients may be candidates for local surgery or a more extensive one, candidates for radiotherapy or Preoperative chemotherapy to maximize the likelihood of resection with cancer-free margins [14,15].

Endoscopic ultrasonography has a definite role in the preoperative staging of rectal cancer, its introduction has increased the ability to delimit the rectal wall layers and thus evaluate the depth of tumor invasion (T) and some minor extent, and the presence of regional lymphatic metastases $(\mathrm{N})$. Tumors generally appear as hypoechoic masses and nodules as round or oval hypoechoic structures compared to perirectal fat. It is reported that staging has a strong impact on the therapeutic decision of the type of surgery required for middle and lateral rectal tumors and the need for neoadjuvant therapies, in addition to follow-up after curative therapy [16-18].

The benefits of neoadjuvant therapy are supported by several studies that show the decrease in local recurrence in patients with locally advanced rectal tumors. Through the precision of preoperative rectal staging, endoscopic ultrasonography facilitates the 
selection of patients with advanced locoregional T3 or T4 disease in whom preoperative neoadjuvant therapy offers more benefits, several studies report a sensitivity of $99 \%$ and a specificity of $89 \%$ [19-21]. Local recurrence after surgery alone for advanced rectal cancer is approximately $25 \%$ and decreases approximately $10 \%$ after radiation, this risk increases in the first 2 years after surgery and early detection may result in Survival improvement if treated early $[9,10]$.

For the above, when performing a critical review of the international literature on different meta-analyzes, pathophysiological studies, among others, conducted in developed countries with high rates of CRC such as Japan, USA, China, Italy, Greece and Australia [7,11,22-25], and based on experience in performing endoscopic ultrasonography, the authors assume that the introduction of endoscopic ultrasonography in Cuba is a very important clinical technology, with great impact on the management of patients with rectal cancer. It represents a valuable tool in the evaluation, and subsequent evolution of patients with rectal tumors. The combination of endoscopic visualization and high-frequency ultrasound imaging allows diagnosis and staging, in a safe and accurate way, which facilitates the decision making of therapeutic behavior both oncological, surgical or combined, which allows to offer cancer patient a higher quality care with a view to favorable evolution and satisfactory results.

The National Center for Minimum Access Surgery, in order to guarantee health care with the highest possible quality, has conducted some research for the first time on the subject, and since then has recommended conducting a study on the efficacy of endoscopic ultrasonography in rectal tumors before surgical treatment, and establish follow-up guidelines in them as a line of investigation.

\section{Conclusion}

Endoscopic ultrasonography is undoubtedly one of the most innovative and accurate techniques in our days at the time of the initial stage of rectal tumors and subsequent monitoring of the occurrence of recurrence, this allows us to choose the appropriate therapeutic behavior both at the beginning and in the evolution of the cancer patient.

\section{Bibliography}

1. Solís A Lesly., et al. "Utilidad del ultrasonido transrectal sin balon en la estadificacion preoperatoria del cancer rectal". Revista Chilena de Radiología 15(2009):19-27.

2. Ministerio de Salud Pública. "Dirección Nacional de Estadísticas y Registros Médicos. Anuario estadístico de salud 2017. La Habana: MINSAP; 2017". Mortalidad por tumores malignos según localización (2016): 65
3. Vila JJ., et al. "Estadificación del cáncer de recto mediante ultrasonografía endoscópica: correlación con la estadificación histológica". Revista Espanola de Enfermedades Digestivas 99 (2007): 132-137.

4. Saitoh N., et al. "Evaluation of echographic diagnosis of rectal cancer using intrarectal ultrasonic examination". Diseases of the Colon and Rectum 29(1986):234-242.

5. Pappalardo G., et al. "The value of endoluminal ultrasonography and computed tomography in the staging of rectal cancer: A preliminary study". Journal of Surgical Oncology 43(1990):219-222.

6. Meining A., et al. "You get what you expect? A critical appraisal of imaging methodology in endosonographic cancer staging". Gut 50(2002):599.

7. Harewood GC. "Assessment of Publication Bias in the Reporting of EUS Performance in Staging Rectal Cancer". The American Journal of Gastroenterology 100(2005):808.

8. Beets-Tan RGH and Beets GL. "Rectal cancer: how accurate can imaging predict the $\mathrm{T}$ stage and the circumferential resection margin?" International Journal of Colorectal Disease 18(2003):385-391.

9. Cesmeli E. "Anorectal staging: is EUS necessary?" Minerva Medicine 105(2014):423-436.

10. Yimei J., et al. "A comparison between the reference values of MRI and EUS and their usefulness to surgeons in rectal cancer". European Review for Medical and Pharmacological Sciences 16(2012):2069-2077.

11. Liang TY., et al. "Imaging paradigms in assessment of rectal carcinoma: loco-regional and distant staging". Cancer Imaging 12(2012):290-303.

12. Swanson RS., et al. "The Prognosis of T3N0 Colon Cancer Is Dependent on the Number of Lymph Nodes Examined". Annals of Surgical Oncology 10(2003):65-71.

13. Balch G-C., et al. "Modern management of rectal cancer: a 2006 update". World Journal of Gastroenterology 12(2006):31863195.

14. National Comprehensive Cancer Network NCCN. Rectal Cancer. NCCN Clinical Practice Guidelines in Oncology. Plymouth, PA: NCCN Group (2018).

15. Avallone A., et al. "Multidisciplinary Approach to Rectal Cancer: Are we Ready for Selective Treatment Strategies?" AntiCancer Agents in Medicinal Chemistry 13(2013):852-860. 
16. Ecografia e oncologia. In: Catalano O, Siani A, editors. Ecografia in oncologia: Testo-Atlante di ultrasonologia diagnostica e interventistica dei tumori. Milano: Springer Milan (2007): $1-25$.

17. Puli SR., et al. “Accuracy of Endoscopic Ultrasound to Diagnose Nodal Invasion by Rectal Cancers: A Meta-Analysis and Systematic Review". Annals of Surgical Oncology 16(2009):12551265.

18. Gleeson FC. "EUS in rectal cancer: anorectal anatomy". In: Hawes RH, Fockens P, Varadarajulu S, eds. Endosonography. 3rd ed. Philadelphia: WB Saunders (2015):260-268.

19. Edelman BR and Weiser MR. Endorectal ultrasound: its role in the diagnosis and treatment of rectal cancer". Clinics in Colon and Rectal Surgery 21(2008):167-177.

20. Vanagunas A., et al. "Accuracy of endoscopic ultrasound for restaging rectal cancer following neoadjuvant chemoradiation therapy". The American Journal of Gastroenterology 99(2004):109-112.

21. Marone P., et al. "Accuracy of endoscopic ultrasound in staging and restaging patients with locally advanced rectal cancer undergoing neoadjuvant chemoradiation". Clinics and Research in Hepatology and Gastroenterology 35(2011):666670.

22. Samee A and Selvasekar CR. "Current trends in staging rectal cancer". World Journal of Gastroenterology 17(2011):828834.

23. Knight CS., et al. "Utility of endoscopic ultrasound-guided fine-needle aspiration in the diagnosis and staging of colorectal carcinoma". Diagnostic Cytopathology 41(2013):10311037.

24. Muradali D and Goldberg DR. US of gastrointestinal tract disease". Radiographics 35(2015):50-68.

25. Cârțână ET., et al. "Advances in endoscopic ultrasound imaging of colorectal diseases". World Journal of Gastroenterology 22(2016):1756-1766.

\section{Volume 2 Issue 9 November 2019}

(C) All rights are reserved by Raúl Antonio Brizuela

Quintanilla., et al. 